Çukurova Üniversitesi Mühendislik Mimarlık Fakültesi Dergisi, 35(1), ss. 263-270, Mart 2020

Çukurova University Journal of the Faculty of Engineering and Architecture, 35(1), pp. 263-270, March 2020

\title{
Yaya Yollarında Kullanılan Farklı Zemin Döşeme Malzemelerinin Kullanım Performanslarının Belirlenmesi
}

\author{
Ali SARIIŞIK ${ }^{* 1}$, Songül CAN ${ }^{1}$ \\ ${ }^{1}$ Harran Üniversitesi, Mühendislik Fakültesi, Inşaat Mühendisliği Bölümü, Şanlıurfa
}

Geliş tarihi: 11.02.2020 Kabul tarihi: 15.05 .2020

\section{$\ddot{\mathbf{O} z}$}

$\mathrm{Bu}$ çalışma, inşaat sektöründe kullanılan döşeme malzemelerinin kullanım alanlarındaki performanslarının belirlenmesi için yeni bir deney yöntemi olan bilye düşürme cihazı kullanılarak yapılan bir araştırmayı kapsamaktadır. Deneysel çalışmalarda zemin döşemesinde yaygın olarak kullanılan 4 farklı doğal taş, beton ve asfalt malzemeleri tercih edilmiştir. Bu çalışma üç bölümden oluşmaktadır: (1) bilye düşürme test cihazı kullanılarak malzemelerin, kopma enerjisi ve çarpma dayanımı değerlerinin belirlenmesi; (2) Griffith teorisi ile kırılma gerilmesinin hesaplanması ve (3) verilerin istatistiksel varyans analizi (ANOVA) ve K-ortalamalar kümeleme yöntemi ile sınıflandırılmasından oluşmaktadır. Bu deneylerden elde edilen veriler yardımıyla malzemelerin kopma enerjisi, çarpma dayanımı ve kırılma gerilmesi istatistiksel $\mathrm{K}$ ortalamalar kümeleme yöntemi ile kırılma potansiyeli indeksi belirlenmiştir. Malzemelerin belirlenen istatistiksel analiz sonuçları dikkate alınarak, kopma enerjisi, çarpma dayanımı ve kırılma gerilmesi sınıflandırılmış, kullanım alanlarındaki performansları belirlenmiştir. Yapılan analizler sonucunda, kırılma potansiyeli açısından beton örnekleri hariç sırasıyla; asfalt, granit, kireçtaşı, mermer ve bazalt örnekleri döşeme malzemesi olarak kullanılabilir.

Anahtar Kelimeler: Zemin döşeme malzemesi, Kopma enerjisi, Çarpma dayanımı, Kırılma gerilmesi, Kullanım performansı

\section{Determination of the Usage Performance of Different Flooring Materials Used on Pedestrian Roads}

\begin{abstract}
This study includes research conducted with the impact strength test which is a new test method for determining the performances of the flooring materials used in the construction industry. In experiment studies, 4 different natural stone, concrete and asphalt materials were used, which are widely used in flooring. This study consists of 3 episodes; (1) Determining the values of materials of rapture energy and impact strength by using ball drop test equipment; (2) Calculating of breaking stress by using Griffith theory and (3) Statically analysis of variance (ANOVA) and classification ok K-average clustering method. By using statically $\mathrm{K}$ average clusture method and breaking potential index; rapture energy, impact strength and breaking stress of materials was determined by helping obtained data. Taking into account of the determined statistical analysis results of the materials, the rapture energy, impact strength
\end{abstract}

*Sorumlu yazar (Corresponding author): Ali SARIIȘIK, sariisikali@gmail.com 
and breaking stress have been classified and their performance in the areas of usage has been determined. As a result of the analysis, except for concrete samples in term of breaking potential, respectively; asphalt, granite, limestone, marble and basalt samples can be used as flooring materials.

Keyword: Floor covering materials, Rapture energy, Impact strength, Fracture stress, Usage performance

\section{GÍRIŞ}

Ülke nüfuslarının sürekli artması yeni yerleşim yerlerine olan ihtiyac1 da beraberinde getirmektedir. Bir ülkenin gelişmişlik düzeyi, yerleşim yerleri olan yaya yolları ve yeşil alanlarda yapılan yaya içi yolların kaplanmasıdır. Kaplama yüzeyindeki yağış suları, enine eğimle kenarlara akıtılarak uzaklaştırılabildiği gibi, yolun üstyapısı geçirimli inşa edilerek de daha hızlı bir şekilde uzaklaştırılabilir. Park ve bahçelerde, cadde ve sokaklarda, gezinti yolları ve dinlenme alanlarının tabanları doğal taş, beton, küp taşlar ve asfalt gibi birçok malzeme ile kaplanmaktadır.

Doğal taş seçimi yapılırken kullanım yerlerine ve kullanım alanlarına uygun boyutlu malzeme seçimi yapılmalıdır. Doğal taşın boyut olarak uygun olup olmadığının belirlenmesinde ise kalite kontrol rol oynamaktadır [1-4]. Doğal taş blokları, ocaktan alınıp üretildikten sonra son ürün așamasına kadar ortaya çıkan plaka, levha ve fayansların kullanım yerlerine uygun seçilip seçilmediği kalite kontrol ile belirlenebilmektedir [5]. İç ve dış mekanlarda; kaplama ve zemin döșemesi olarak kullanılan doğal taşların, çarpmaya karşı dayanıklılığının belirlenmesi piyasa için önem arz etmektedir. Kaplama ve zemin döşemesi olarak kullanılan doğal taş nihai ürünlerinin, kırılma riskini asgari seviyeye indirmek için doğal taş plakalarının kalınlığının belirlenmesi gerekmektedir.

Literatür çalışmalarına bakıldığında; doğal taşların fiziko-mekanik özellikleri ve çevre etkileşim özellikleri dikkate alınarak, kullanım alanları ve sınıflandırması ile ilgili birçok çalı̧̧ma yapılmıştır [6-10].

Kullanım ömrünün uzun sürmesi, renk ve desen çeşitliliği gibi nedenlerden dolayı doğal taşlar tercih edilmektedir. Aksaray yaylak granitlerinin kaplama olarak değerlendirilmesi üzerine yapılan çalışmada mekanik özellikler incelenmiş̧ir.
Yaylak granitlerinin TS 6234'e göre kaplama taş1 olarak kullanılabileceği sonucuna varılmıştır. Granitler çevre ve atmosfer koşullarına karşı dayanıklı, paslanmaz, renk- desen çeşitliliğ̈in fazla olması, granit plakaların kenar ve köşelerinin düzeltme sırasında çatlamaması gibi avantajlardan dolayı tercih edilmektedir [11].

Granitler dış ortam şartlarına ve aşınmaya karş1 dayanıklı, iyi cila tutma özelliğine sahip, renklerini ve parlaklıklarını uzun süre koruyan malzemeler olması sebebiyle bordür, döşeme kaplaması, merdiven, duvar kaplaması olarak tercih edilmektedir [12-13].

Birçok araştırmacının yaptıkları çalışmalarda, doğal taş örneklerinin kopma enerjisi, çarpma dayanımı ve farklı bir cihaz ile de sıçrama katsayısı değerlerinin belirlemesi için bir deney yöntemi geliştirmeye çalışılmıştır [14-18]. Bu çalışmada, zemin döşeme malzemelerinin kopma enerjisi ve çarpma dayanımı verilerinden yararlanılarak, kırılma gerilmesi belirlenmiștir. $\mathrm{Bu}$ veriler kullanılarak, istatistiksel $\mathrm{K}$ ortalamalar kümeleme yöntemi ile kırılma potansiyeli indeksi belirlenmiştir. Ayrıca, yaya yollarında kullanılan farklı doğal taş örneklerinin beton ve asfalt malzemeleri performansları ile karşılaştırılması yapılmıştır.

\section{MATERYAL VE METOT}

\subsection{Materyal}

$\mathrm{Bu}$ çalı̧̧mada, inşaat sektöründe, özellikle zemin döşemesi ve kaplaması olarak kullanılan mermer, kireçtaşı, bazalt, granit, beton ve asfalt seçilmiştir. Doğal taş örnekleri piyasada en çok kullanılan Afyon mermeri, Karacadağ Bazaltı, Bilecik Kireçtaşı ve Yaylak Graniti kullanılmıştır. Beton (Poroz beton) için gerekli olan çimento ve agrega oranı, karışım suyunun çimento miktarına oranı, betonun dayanımını etkilemektedir. Beton (Poroz 
beton) örnekleri ise su/çimento oranı 0,5 olan, farklı tane boyutlarında asidik ponza içerikli \%1'i oranında süper akışkanlaştırıcı katkılıdır [19]. Asfalt malzeme olarak da bitümlü sıcak karışım asfalt tercih edilmiştir [20]. Çizelge 1 'de doğal taşların örnek kodları, plaka boyutları, yüzey işlem metodu ve ticari isimleri verilmektedir. Çalışma kapsamında toplamda 36 örnek (6 farklı malzeme x 6 adet örnek) üzerinde çarpma dayanımı deneyleri yapılmıştır.

Çizelge 1. Deneyde kullanılan malzemelerin örnek kodları, plaka boyutları ve ticari isimleri

\begin{tabular}{|l|c|c|}
\hline Ticari İsim & Kod & Plaka Boyutu $(\mathrm{mm})$ \\
\hline Mermer & D1 & $200 \times 200 \times 30$ \\
\hline Bazalt & D2 & $200 \times 200 \times 30$ \\
\hline Granit & D3 & $200 \times 200 \times 30$ \\
\hline Kireçtaş1 & D4 & $200 \times 200 \times 30$ \\
\hline Asfalt & A1 & $100(\mathrm{D}) \times 30(\mathrm{~h})$ \\
\hline Beton (Poroz beton) & B1 & $100 \times 100 \times 30$ \\
\hline
\end{tabular}

\subsection{Deneysel Çalışmalar}

Zemin döşeme malzemelerinin kontrolü için TS EN 14158 standardına göre çarpma etkisi ile kopma enerjisi bilye düşürme test cihazı kullanılarak test edilmiștir [21]. Malzeme örnekleri sabit kütleye ulaşıncaya kadar $(70 \pm 5){ }^{\circ} \mathrm{C}$ sıcaklıkta kurutulmuştur. (24 \pm 2$) \mathrm{h}$ aralığında bulunan iki tartım arasındaki fark, ilk kütlenin \%0,1'inden büyük değilse sabit kütleye erişilmiş olduğu varsayılır. Bilye düşürme test cihazı, $1043 \mathrm{~g}$ ağırlığına sahip, zemini kum ile doldurulmuş bir hazne, çelik bir bilye ve bu çelik bilyeye bağlı yüksekliği ayarlanabilen bir bilye yatağından oluşmaktadır (Şekil 1). Çarpma dayanımı deneyi gerçekleştirilirken ilk olarak; çelik bilye 0-100 cm yükseklikten birakılarak, kumlu zemine yerleștirilmiş olarak bulunan malzemelerin üzerine birakılmaktadır. Test edilecek 6 numuneden biri "kontrol numunesi" olarak seçilmektedir. Numunenin kırılmaması halinde, düşüş yüksekliği kırılma gerçekleșene kadar $50 \mathrm{~mm}$ arttırılır. Kontrol numunesinin kırıldığı yükseklik (ht) kaydedilir. $\mathrm{Bu}$ deney diğer beş numune ile hi $=($ ht -150$) \mathrm{mm}$ ve en az 100 mm'lik başlangıç yüksekliğinden başlanarak tekrarlanır. Her bir numune için kopma yüksekliği kaydedilir. Numunenin ilk çarpmada kırılması halinde, sonuç geçersiz kabul edilir.

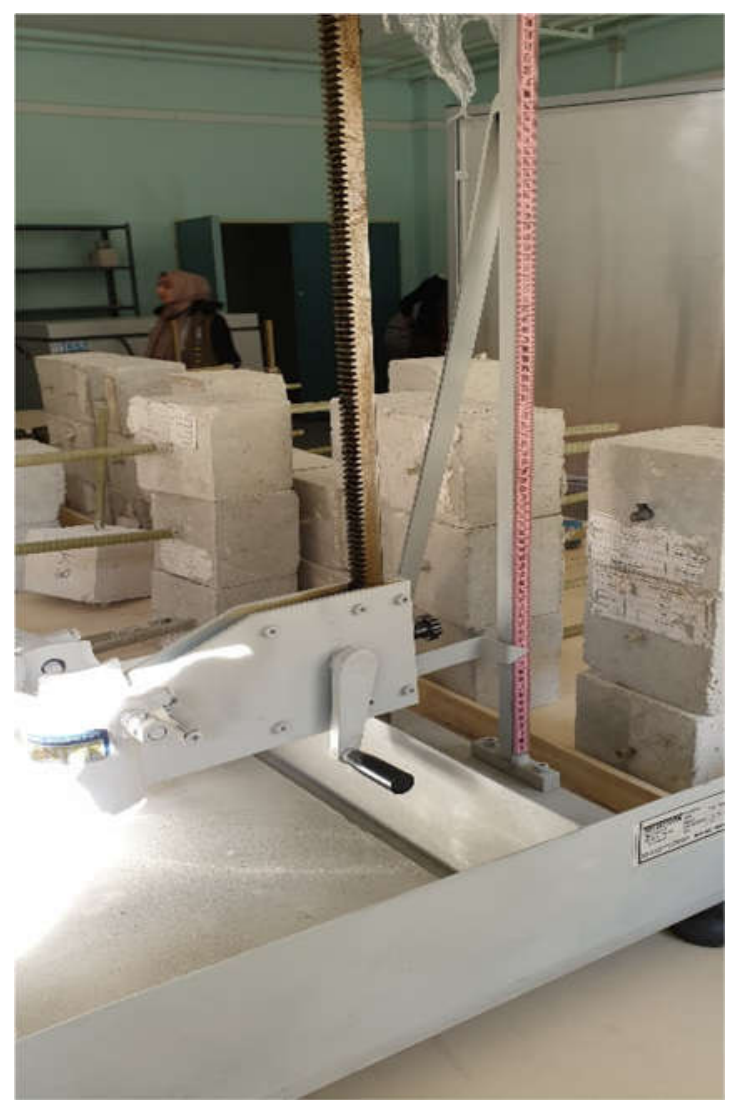

Şekil 1. Çarpma dayanımı test cihazı

Bilye düşürme deney yöntemi Şekil 2'de ayrıntılı olarak gösterilmiştir. Öncelikle, örnekler kumlu zemin üzerinde bulunan işaretli alana yerleştirilmiştir. Yapılan ön denemeler neticesinde, bilyenin düşme yüksekliği $25 \mathrm{~cm}$ olarak ayarlanmış ve bu yüksekliğe bağlı düşüş gerçekleştirilmiştir. Bilyenin ilk düşürülmesi sonucunda, ok ile belirtilen alanda bir iz oluşmuştur. 6. vuruş sonrası $25 \mathrm{~cm}$ yükseklikten bırakılan bilye ile numune yüzeyindeki iz artmıştır. Kırılmanın gerçekleşebilmesi için bilyenin düşme yüksekliği $5 \mathrm{~cm}$ arttırılarak, $30 \mathrm{~cm}$ 'e çıkarılmıştır. Bilyenin düşme yüksekliğinin $30 \mathrm{~cm}$ olarak ayarlanması sonucunda; 3 . vuruşta numune çatlamış ve 4 . vuruşta ise numune kırılmıştır. 


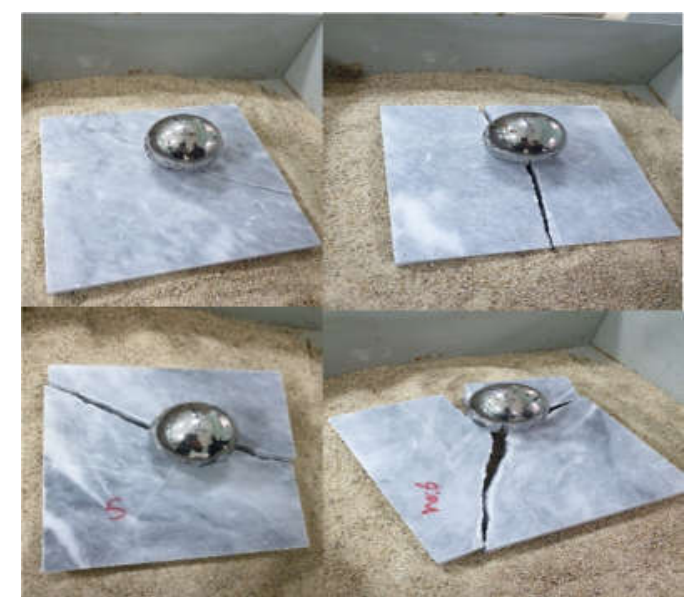

Şekil 2. Çarpma etkisi ile kopma enerjisi deneyinde örnek kırılma şekli

Malzemelerin kopma enerjisi TS EN 14158 standardına göre aşağıdaki bağıntılardan yararlanılarak hesaplanmıştır (Eşitlik 1-4).

$\mathrm{W}=\mathrm{m} \times \mathrm{g} \times \mathrm{h}$

$\mathrm{W}$ : Kopma enerjisi (Nm, joule),

h: Çelik bilyenin kopma yüksekliği (m)'dir.

g: Yer çekimi ivmesi $\left(9,806 \mathrm{~m} / \mathrm{s}^{2}\right)$,

m: Çelik bilyenin kütlesi (kg)' dır.

Sarışık (2012) tarafından doğal taşların çarpma dayanımının aşağıdaki bağıntılardan yararlanılarak hesaplanması öngörülmüştür.

$C ̧ D=\frac{\mathrm{W}}{\mathrm{V}}$

Burada;

ÇD: Çarpma dayanımı, N/mm², $\mathrm{MPa} / 10^{-3},(\mathrm{kPa})$

$\mathrm{V}$ : Deney örneğinin hacmi, $\left(\mathrm{mm}^{3}\right)$,

$\mathrm{W}$ : Toplam darbe işi, ( $\mathrm{N}$ x mm)' dir.

$\mathrm{W}=\mathrm{W}_{1}+\mathrm{W}_{2}+\mathrm{W}_{\mathrm{n}}=\mathrm{G} \cdot \mathrm{h}_{1}+\mathrm{G} \cdot \mathrm{h}_{2}+\mathrm{G} \cdot \mathrm{h}_{\mathrm{n}}$

Burada;

G: Çelik bilyenin ağırlı̆̆ $1,(\mathrm{~N})$,

$\mathrm{h}_{1}, \mathrm{~h}_{2}, \mathrm{~h}_{\mathrm{n}}$ : Çelik bilyenin düşme yükseklikleri, (mm)'dir.
$\mathrm{G}=\mathrm{m} \times \mathrm{g}$

$\mathrm{g}$ : Yerçekimi ivmesi, $\left(\mathrm{m} / \mathrm{s}^{2}\right)$,

m: Çelik bilyenin kütlesi, (kg)'dır.

Asfalt ve beton numunelerinin boyutları farklıdır. Deney sonuçlarının karşılaştırılması için asfalt örnekleri için 0,2 ile beton numuneleri 0,25 düzeltme katsayısı ile çarpma dayanımı boyutuna dönüşüm sağlanmıştır (Eşitlik 5-6) [22].

Asfalt çarpma dayanım $20 * 20 * 3 \mathrm{~cm} \cong$

Asfalt çarpma dayanım $10 * 3 \mathrm{~cm} * 0,2$

Beton çarpma dayanım $20 * 20 * 3 \mathrm{~cm} \cong$

Beton çarpma dayanım d0*10*3cm $* 0,25$

Griffith kırılma teorisi dikkate alınarak, malzemelerin çekme etkisinde çatlak ucunda oluşan maksimum kırılma gerilmesi Eşitlik 7'de gösterilmiştir. Griffith teorisine göre gevrek malzeme ince çatlaklar içerir. Çatlak uçlarında oluşan gerilmeler maksimum seviyeye gelince çatlaklar yayılır ve yayılan çatlak yüzeyinde enerji yığılmaları gözlemlenir. Oluşan bu enerji yığılmaları elastik enerjidir. Griffith teorisi ile çatlağın yayılmaya başladığı an ifade edilir.

$\sigma_{\text {max }}=2 \sigma_{0}\left(\frac{\mathrm{a}}{\rho_{\mathrm{t}}}\right)^{\frac{1}{2}}$

Çatlak ucunda oluşan maksimum gerilme hesaplanırken denklemdeki her bir sembol aşağıdaki şekilde ifade edilmiştir;

$\sigma_{\max }:$ Çatlak ucundaki maksimum gerilme $\left(\mathrm{N} / \mathrm{mm}^{2}\right)$

$\sigma_{0}$ : Uygulanan çekme gerilmesi $\left(\mathrm{N} / \mathrm{mm}^{2}\right)$

a: Çatlak boyu (mm)

$\rho_{t}$ : Çatlak ucu eğrilik çapı $(\mathrm{mm})$

(3) Çatlağın düz olması durumunda çatlak boyu (a), düz olmaması durumunda çatlak boyunun yarısı alınmıştır. Çatlak ucu eğrilik çapı $\left(\rho_{t}\right)$ doğal taşlarda $5 \mathrm{~cm}$, asfalt örneğinde $2 \mathrm{~cm}$ ve beton örneğinde $3 \mathrm{~cm}$ olarak kabul edilmiştir. 


\section{BULGULAR}

\section{DEĞERLENDİRMELER}

\subsection{Zemin Döșeme Malzemelerinin Kopma Enerjisi, Çarpma Dayanımı ve Kırılma Gerilmesi Analizi}

Çalışmada çarpma dayanımı deneylerinde kullanılan 6 farklı malzemenin kopma enerjisi, çarpma dayanımı ve kırılma gerilmesi değerlerinin istatistiksel olarak analizi yapılmıştır.
VE Malzemelerin kopma enerjisi, çarpma dayanımı ve kırılma gerilmesi (6 malzeme x 5 örnek) varyans (ANOVA) analizi uygulanmıştır. Zemin döşeme malzemelerin kopma enerjisi, çarpma dayanımı ve kırılma gerilmesi bakımından $\mathrm{p}<0.001$ anlamlılık düzeyinde istatistiksel olarak anlamlı fark olduğu gözlemlenmiştir (Çizelge 2).

Malzemelerin kopma enerjisi, çarpma dayanımı ve kırılma gerilmesine göre çarpma dayanımı değerleri Şekil 3'de verilmektedir.

Çizelge 2. Malzemelerin kopma enerjisi, çarpma dayanımı ve kırılma gerilmesine göre istatistiksel analizi

\begin{tabular}{|l|c|c|c|c|c|c|}
\hline \multirow{2}{*}{ Parametreler } & \multicolumn{2}{|c|}{ Küme } & \multicolumn{2}{c|}{ Hata } & \multirow{2}{*}{$\begin{array}{c}\text { Anlamlılik } \\
\text { Düzeyi }\end{array}$} \\
\cline { 2 - 5 } & Ortalama Kare & df & Ortalama Kare & df & & $<0,001$ \\
\hline Kopma Enerjisi(J) & 38,624 & 3 & 0,034 & 26 & 1152,667 & $<0,001$ \\
\hline Çarpma Dayanımı(kPa) & 49,448 & 3 & 0,023 & 26 & 2126,998 & $<0,001$ \\
\hline Kırılma Gerilmesi $(\mathrm{kPa})$ & 197,065 & 3 & 0,372 & 26 & 529,302 & $<0,001$ \\
\hline
\end{tabular}

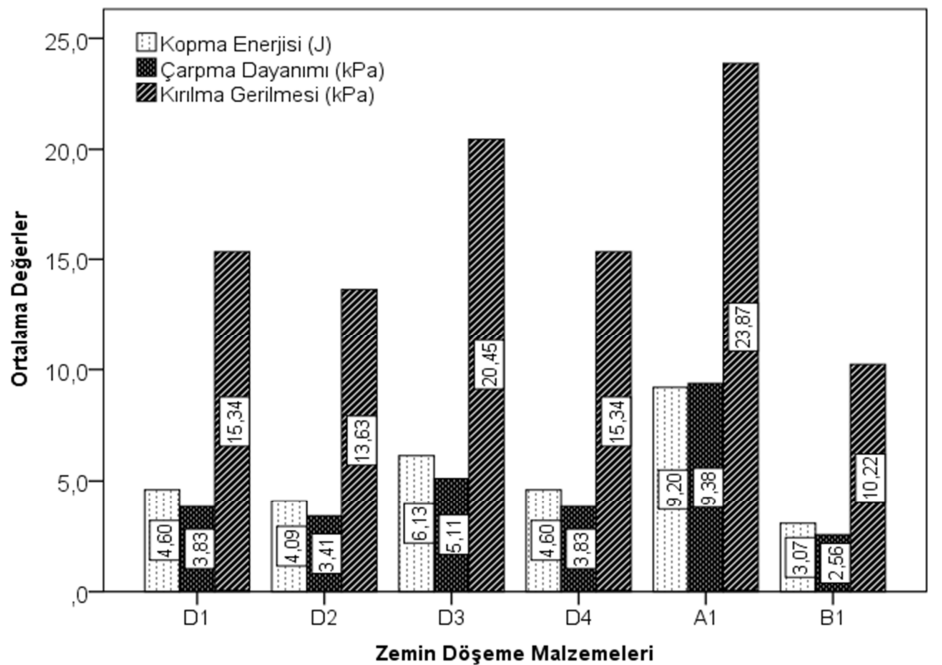

Şekil 3. Malzemelerin kopma enerjisi, çarpma dayanımı ve kırılma gerilmesi değerleri

Zemin döşeme malzemelerinde beton (B1) örneği, kopma enerjisi, çarpma dayanımı ve kırılma gerilmesinde en düşük değerde olduğu görülmektedir. B1 örneği kopma enerjisi 3,07 J, çarpma dayanımı 2,56 kPa ve kırılma gerilmesi $10,22 \mathrm{kPa}$ 'dır. Buna göre (B1) örneği kırılma riski en yüksek değerdedir. Asfalt (A1) örneği, kopma enerjisi, çarpma dayanımı ve kırılma gerilmesinin en yüksek değerde olduğu görülmektedir. A1 örneği kopma enerjisi 9,2 J, çarpma dayanımı
9,38 kPa ve kırılma gerilmesi 23,87 kPa'dır. Buna göre (A1) örneği kırılma riski en düşük değerdedir.

Zemin döşeme malzemelerinde 4 farklı doğal taşlardan granit (D3) örneği diğer mermer (D1), bazalt (D2) ve kireçtaşı (D4) örneklerinden daha yüksek değer almışlardır. Bazalt (D2) örneği kopma enerjisi, çarpma dayanımı ve kırılma gerilmesi en düşük değer almıştır. Buna göre doğal taşlarda zemin döşeme malzemesi olarak granit tercih edilmelidir. 
3.2. Zemin Döşeme Malzemelerinin Kırılma Potansiyeli İndeksinin Belirlenmesi ve Sinıflandırılması istatistiksel $\mathrm{K}$ ortalamalar kümeleme yöntemi ile analiz edilerek, kırılma potansiyeli indeksi belirlenmiştir (Çizelge 3).

Zemin döşeme malzemeleri çarpma dayanımı, kopma enerjisi ve kırılma gerilmesi değerleri

Çizelge 3. Malzemelerin istatistiksel K ortalamalar kümeleme yöntemi ile kırılma potansiyeli indeksi

\begin{tabular}{|c|c|c|c|}
\hline $\begin{array}{c}\text { Çarpma Dayanımı } \\
(\mathrm{kPa})\end{array}$ & Kopma Enerjisi (J) & Kirılma Gerilmesi $(\mathrm{kPa})$ & $\begin{array}{c}\text { Kirılma Potansiyeli } \\
\text { İndeksi }\end{array}$ \\
\hline$<2,56$ & $<3,07$ & $<10,22$ & Çok Yüksek (ÇY) \\
\hline $2,56-3,69$ & $3,08-4,43$ & $10,23-14,77$ & Yüksek (Y) \\
\hline $3,69-5,11$ & $4.43-6,14$ & $14,78-20,45$ & Orta(O) \\
\hline $5,11-9,38$ & $6,14-9,20$ & $20,45-23,87$ & Düşük (D) \\
\hline$>9,38$ & $>9,20$ & $>23,87$ & Çok Düşük(ÇD) \\
\hline
\end{tabular}

Malzemelerin istatistiksel $\mathrm{K}$ ortalamalar kümeleme yöntemi ile kırılma potansiyeli indeksi dikkate alınarak, sinıflandırması yapılmıştır (Çizelge 4).

Çizelge 4. Malzemelerin istatistiksel $\mathrm{K}$ ortalamalar kümeleme yöntemi ile kırılma potansiyeli indeksi göre sinıflandırılması

\begin{tabular}{|c|c|c|c|c|}
\hline $\begin{array}{c}\text { Zemin Döşeme } \\
\text { Malzeme Kodu }\end{array}$ & $\begin{array}{c}\text { Çarpma Dayanımı } \\
(\mathrm{kPa})\end{array}$ & $\begin{array}{c}\text { Kopma Enerjisi } \\
(\mathrm{J})\end{array}$ & $\begin{array}{c}\text { Kirılma Gerilmesi } \\
(\mathrm{kPa})\end{array}$ & $\begin{array}{c}\text { Kırılma } \\
\text { Potansiyeli }\end{array}$ \\
\hline D1 & 3,83 & 4,60 & 15,34 & $\mathrm{O}$ \\
\hline D2 & 3,41 & 4,09 & 13,63 & $\mathrm{O}$ \\
\hline D3 & 5,11 & 6,13 & 20,45 & $\mathrm{D}$ \\
\hline D4 & 3,83 & 4,60 & 15,33 & O \\
\hline A1 & 9,38 & 9,20 & 23,87 & ÇD \\
\hline B1 & 2,56 & 3,07 & 10,22 & ÇY \\
\hline
\end{tabular}

Zemin döşeme malzemelerinden (B1) örneğinde; çarpma dayanımı 2,56 kPa, kopma enerjisi, 3,07 ve kırılma gerilmesi $10,22 \mathrm{kPa}$ olduğu için kırılma potansiyeli çok yüksek seviyededir. A1 örneği; çarpma dayanımı 9,38 kPa, kopma enerjisi, 9,20 ve kırılma gerilmesi $23,87 \mathrm{kPa}$ olduğu için kırılma potansiyeli çok düşük seviyededir. Kırılma potansiyeli sınıflandırmasına göre, beton (poroz beton) (B1) örnekleri hariç diğer örnekler zemin döşeme ve kaplama malzemesi olarak kullanılabilir olduğu öngörülmüştür.

\section{SONUÇLAR}

Yapılan bu deneysel çalışmalar sonucunda, zemin kaplama malzemesi olarak kullanılacak malzeme örneklerinin çarpma dayanımı, kopma enerjisi ve kırılma gerilmesi değerleri belirlenmiştir. Elde edilen değerler kullanılarak, istatistiksel $\mathrm{K}$ ortalamalar kümeleme yöntemi ile kırılma potansiyeli indeksi belirlenmiş ve sınıflandırılmıştır. Aşağıda bu deneysel çalışmalardan elde edilen sonuçlar özetlenmektedir:

- Zemin döşeme malzemelerinin çarpma dayanımı, kopma enerjisi ve kırılma gerilmesi bakımından $\mathrm{p}<0,001$ anlamlılık düzeyinde tüm örneklerde istatistiksel olarak anlamlı fark vardır. Buna göre zemin kaplaması olarak kullanımında çarpma dayanımı, kopma enerjisi ve kırılma gerilmesinin etkili olduğu görülmektedir.

- Kırılma potansiyeli sınıflandırmasına göre; beton örnekleri hariç sırasıyla 
asphalt, granit, kireçtaşı, mermer ve bazalt örneklerin; zemin döşeme malzemesi olarak kullanılabilir olduğu öngörülmüştür.

\section{TEŞEKKÜR}

$\mathrm{Bu}$ araştırma çalışmasında kullanılan Beton (Poroz Beton) numuneler Yük. Müh. Adile MANCI'nın ve Asfalt numuneler Yük. Müh. Nur Erdem AKGÜL ŞEKER'in Yüksek Lisans tezlerinden üretmiş olduğu için kendilerine teşekkürlerimizi sunarız. Ayrıca deneylerin yapılmasında yardımcı olan, katkı sunan Lisans öğrencilerimiz, Ahmet Nur ALHAJ, Kusey ALYUSUF'da teşekkür ederiz. Araştırmamızdaki kullanılan verilerin üretilmesinde katk1 sunan HÜBAP 19101, 19102 ve 17178 numaralı projelere de teşekkür ederiz.

\section{KAYNAKLAR}

1. Senturk, A., Gunduz, L., Tosun, Y.L., Sariisik, A., 1996. Marble Technology. Tugra Press, 242, Isparta.

2. Kulaksız, S., 2007. Natural Stone (Marble) Mining and Processing Technologies, TMMOB Chamber of Mining Engineers, 634, Ankara.

3. Sarıș1k, A., 1998. Variation Characteristics in the Environment Interaction and PhysicoMechanic Properties of Calcium Carbonate Marbles, SDU, Ph.D. Thesis, 400, Isparta.

4. Sarıșık, A., Sariisik G., 2010. Quality Control of Turkish Calcareous Natural Stone Using the Merkont System, Journal of Testing and Evaluation, 38(5), 575-587.

5. Onargan, T., Köse, H., Deliormanlı, H., 2005. Mermer. TMMOB Press, 249.

6. Singh, T.N., Singh, S.K., Mishra, A., Singh, P.K., Singh, V.K., 1999. Effect of Acidic Water on Physico Mechanical Behaviour of Rock. Indian Journal of Engineering and Materials Sciences, 6, 66-72.

7. Sharma, P.K., Khandelwal, M., Singh, T.N., 2007. Variation on Physico-mechanical Properties of Kota Stone Under Different Watery Environments. Building and Environment, 42, 4117-4123.
8. Sarışık, A., Sariisik, G., Senturk, A., 2010. Characterization of Physical and Mechanical Properties of Natural Stones Affected by Ground Water Under Different Ambient Conditions, Ekoloji, 77, 88-96.

9. Sarışık, A., Sariisik, G., 2011. Environmental Interaction Properties of Marble Used in the Restoration of Historical Monuments (DalyanKaunos), Ekoloji, 79, 12-20.

10. Rodriquez-Navarro, C., Linares-Fernandez, L., Doehne, E., Sebastian-Pardo, E., 2002. Effects of Ferrocyanide Ions on $\mathrm{NaCl}$ Crystallization in Porous Stone. Journal of Crystal Growth, 243, 503-516.

11. Ang1, O.S., 2007. Aksaray Yaylak Graniti'nin Kaplama Taşı Yönünden Özelliklerinin Araştırılması, Yüksek Lisans Tezi, İstanbul Teknik Üniversitesi Fen bilimleri Enstitüsü, İstanbul.

12. Altınçekiç, H., 2001. Bazı Doğal Taşların İrdelenmesi ve Peyzaj Düzenlemelerinde Kullanım Olanakları, İ. Ü. Orman Fakültesi Dergisi, Seri: B, Cilt: 51, Say1:1, İstanbul.

13. Uzun, G., 1996. Yap1 Materyalleri, Ç. Ü. Ziraat Fakültesi, Genel Yayın No: 148, Ofset Atölyesi, Adana.

14. Kundak, E., 2016. Gerçek Mermerlerin Farklı Ortam Koşullarında Kopma Enerjisi ve Çarpma Dayanımının Belirlenmesi (Doktora Tezi). Eskişehir Osmangazi Üniversitesi Fen Bilimleri Enstitüsü, Eskişehir.

15. Sarışık, G., 2012. Determining Performance of Marble Finished Products on Their Usage Areas by a New Impact-resistance Test Method, Journal of Testing and Evaluation, 40-5, 1-7.

16. Sarıșık, G., Kundak, E., Akdaş, H., Özkan, E., 2012. Mermer Plakalarda Çarpma Dayanımı Deneyi ve Sinıflandırılması, 8. Mermer ve Doğal Taş Kongresinde Sunulmuş Bildiri, Afyonkarahisar.

17. Sarışık, G., Özkan, E., Kundak, E., Akdaş, H., 2016. Classification of Parameters Affecting Impact Resistance of Natural Stones, Journal of Testing and Evaluation, 44-4, 1650-1660.

18. Kundak, E., Akdaş, H., Sarışık, G., 2020. Farklı Kalınlıktaki Bazı Doğal Taşların Kopma Enerjisi ve Çarpma Dayanımının Belirlenmesi. 
Eskişehir Osmangazi Üniversitesi Mühendislik ve Mimarlık Fakültesi Dergisi, 28(1), 62-72.

19. Manc1, A. 2019. Ponza Agregası ile Yeni Ürün Olarak Geliştirilen Yalıtım Plakasında Bor Atığı Kullanılarak Teknik Özelliklerinin İyileştirilmesi, Yüksek Lisan Tezi, Harran Üniversitesi Fen Bilimleri Enstitüsü, Şanlıurfa.

20. Akgül Şeker, N.E., 2020. Bitümlü Sicak Karışımların İklim Şartlarında Bozulmasına Filler Etkisinin Değerlendirilmesi, Yüksek Lisan Tezi, Harran Üniversitesi Fen Bilimleri Enstitüsü, Şanlıurfa.

21. TS EN 14158., 2004. Doğal Taş Deney Metotlar1-kopma Enerjisinin Tayini, Türk Standartları Enstitüsü, Ankara.

22. Alhaj A.N., Alyusuf, K., 2020. Yaya Yollarında Kullanılan Döşeme Malzemelerinin Dayanımının Karşılaştırılması (Çok Disiplinli Entegre Proje Çalışmaları), Harran Üniversitesi, İnşaat Mühendisliği, Şanlıurfa. 